\title{
A[H1N1] flu and refractory hypoxaemia: Is extracorporeal lung support the holy grail?
}

\author{
T V Veenith, M Rana, A Ercole, K Gunning, R Mahroof
}

John Farman Intensive Care Unit, Addenbrooke's Hospital, Cambridge University Hospitals NHS Foundation Trust, Cambridge, UK

\section{Correspondence to} Dr K Gunning, John Farman Intensive Care Unit, Addenbrooke's Hospital, Cambridge University Hospital NHS Foundation Trust, Hills Road, Cambridge CB2 000, UK; kevin.gunning@addenbrookes. nhs.uk

Received 25 February 2011 Accepted 18 March 2011 Published Online First 22 April 2011

\begin{abstract}
There is a call for methodologically robust randomised clinical trials in adult extracorporeal membrane oxygenation for its routine implementation for patients with "failing" conventional ventilation. Adherence to lung protective ventilation strategies, along with fluid balance [if required early renal replacement therapy] and inotropes to support the circulation to minimise ventilator-induced lung injury, may mitigate deterioration requiring extracorporeal lung support. Currently there is no convincing evidence to routinely advocate extracorporeal lung support in failed conventional ventilation, and a prospective trial is needed to define standard best practice and to tailor extracorporeal lung support referral criteria in young patient cohort with severe refractory respiratory failure.
\end{abstract}

'The art of medicine consists of amusing the patient while nature cures the disease.' Voltaire

Dear Doctor, can you review this non-vaccinated 29-year-old female who presented with severe hypoxaemic respiratory failure following a 2-day history of myalgia and flu-like symptoms, with a history of obesity (body mass index (BMI) $40 \mathrm{~kg} / \mathrm{m}^{2}$ ). On admission she was tachypnoeic, feverish, hypoxaemic $\left(\mathrm{PaO}_{2} 6.5 \mathrm{kPa}, \mathrm{FiO}_{2} 0.8\right)$ with four quadrant infiltrates on chest $\mathrm{x}$-ray (CXR) and elevated inflammatory markers (C-reactive protein (CRP) $>250 \mathrm{mg} / \mathrm{l}$ ), with positive PCR for A[H1N1]. Despite employing lung protective ventilation (LPV) using tidal volumes of $<6 \mathrm{ml} / \mathrm{kg}$, positive end-expiratory pressure (PEEP) $15 \mathrm{~cm} \mathrm{H}_{2} \mathrm{O}$, I:E ratio 3:1, with peak pressures of $<30 \mathrm{~cm} \mathrm{H}_{2} \mathrm{O}$ supported by veno-venous haemodiafiltration, maintenance of colloid oncotic pressure and negative fluid balance, her gas exchange has deteriorated. The team caring for her would be grateful for your advice on advanced respiratory support, and her suitability for extracorporeal lung support (ECLS).

\section{CLINICAL PROBLEM}

Triple reassorted $A[\mathrm{H} 1 \mathrm{~N} 1]$ influenza ${ }^{1}$ resulted in $>300$ deaths in the UK in 2010 (Health Protection Agency), with $\sim 70 \%$ of patients dying belonging to the age group of 16-64 years. The demographics of the patients suggest that those admitted to an intensive care unit (ICU) during the current outbreak are younger than patients with seasonal flu. ${ }^{2}$ Severity of illness and ICU mortality in $\mathrm{A}[\mathrm{H} 1 \mathrm{~N} 1]$ is associated with an increasing age, higher organ dysfunction (Sequential Organ Failure
Assessment (SOFA) score), chronic organ dysfunction and immunocompromised states. Even though pregnancy was associated with higher critical care admission rates, as a cohort it was associated with a lower risk of death. ${ }^{12}$

\section{VENTILATORY MANAGEMENT OF REFRACTORY HYPOXIA}

Histopathological data have shown similarities between acute respiratory distress syndrome (ARDS) and $\mathrm{A}[\mathrm{H} 1 \mathrm{~N} 1]$-associated lung injury. ${ }^{3}$ Both cause diffuse alveolar damage, with varying degrees of inflammatory infiltrates and pulmonary haemorrhage. Severe acute lung injury causes a reduction in the static compliance and ventilationperfusion mismatch. Subjecting the lung to excessive volume or pressure during mechanical ventilation (MV) results in an additional alveolar epithelial cell injury-induced inflammatory process that may worsen both lung compliance and gas exchange. Hence, prevention of ventilator-induced lung injury (VILI) due to volutrauma and barotrauma is at the heart of LPV strategy.

The basis of LPV strategy is to use a low tidal volume $\left(\mathrm{V}_{\mathrm{T}} ; 4-8 \mathrm{ml} / \mathrm{kg}\right.$ of ideal body weight), plateau pressure $\leq 30 \mathrm{~cm} \mathrm{H}_{2} \mathrm{O}$, inverse ventilation ratio (I:E) and reduction of oxygen toxicity, and to titrate PEEP to $\mathrm{FiO}_{2}$ to maintain a $\mathrm{PaO}_{2}>8 \mathrm{kPa}$. In the case of $\mathrm{A}[\mathrm{H} 1 \mathrm{~N} 1]$ this strategy would be tolerated by this young cohort of patients. However, resultant hypercapnoea could lead to increased intracranial pressure, myocardial depression, pulmonary hypertension and reduction in renal perfusion. ${ }^{4}$ An evidence-based LPV strategy has been shown to reduce in-hospital and 28 day mortality; currently we allow permissive hypercapnoea to a $\mathrm{pH}>7.2$ and permissive hypoxaemia to $\mathrm{PaO}_{2}>8 \mathrm{kPa}$. Our management algorithm is summarised in figure 1.

\section{ADJUNCTIVE VENTILATOR THERAPIES}

Prone ventilation (PV) can be used in ARDS with refractory hypoxaemia to improve oxygenation. However, improvement in mortality with $\mathrm{PV}$ is seen only in a subset of patients with severe refractory hypoxaemia. This would be difficult in your patient because of high BMI. High frequency oscillatory ventilation (HFOV) is an alternative technique to conventional ventilation in severe hypoxaemic respiratory failure, with little benefit in maintenance of $\mathrm{PaCO}_{2}$. HFOV uses small $\mathrm{V}_{\mathrm{T}}$ (usually less than the anatomical dead space) and is delivered at high frequencies $(3-15 \mathrm{~Hz})$. A recent meta-analysis ${ }^{5}$ has shown a reduction in in-hospital 


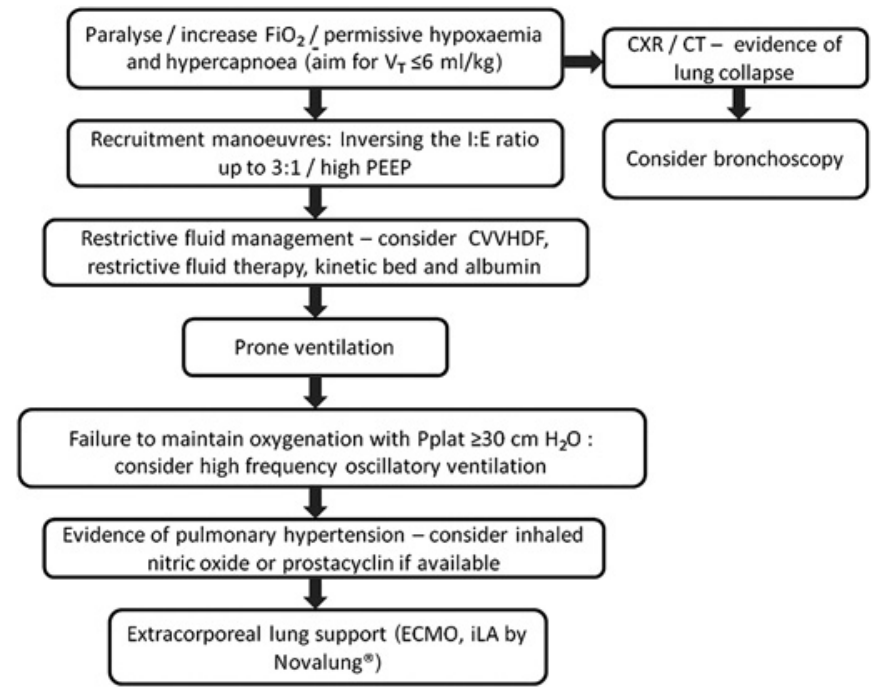

Figure 1 Our algorithm for management of severe refractory respiratory failure. $\mathrm{FiO}_{2}$, fraction of inspired oxygen; $\mathrm{V}_{\mathrm{T}}$, Tidal volume; $\mathrm{l}: \mathrm{E}$, Inspiratory:Expiratory ratio; PEEP, Positive end-expiratory pressure; CVVHDF, Continuous Veno Venous Hemodiafiltration; PPlat, Plateau pressure; ECMO, extracorporeal membrane oxygenation; CXR, chest $\mathrm{x}$ ray; CT, computed tomography.

and 30-day mortality along with a reduced risk of 'treatment failure' when compared with conventional ventilation in ARDS. A UK multicentre study into HFOV in ARDS is currently underway (OSCAR Trials No. ISRCTN10416500).

\section{ECLS: EXTRACORPOREAL MEMBRANE OXYGENATION (ECMO) AND EXTRACORPOREAL $\mathrm{CO}_{2}$ REMOVAL $\left(\mathrm{ECCO}_{2} \mathrm{R}\right)$}

ECLS was first used in 1972, and in an ICU setting it encompasses both an $\mathrm{ECCO}_{2} \mathrm{R}$ device (iLA by Novalung, Talheim, Germany) and veno-arterial (VA) or veno-venous (VV) ECMO. ECLS enables the use of a lower $\mathrm{V}_{\mathrm{T}}$, at aptly named 'rest settings' to reduce VILI and any ventilator-associated haemodynamic compromise. ${ }^{6}$ The Glenfield Hospital, Leicester criteria for ECMO are: reversible cause of respiratory failure, $<7$ days high pressure or high $\mathrm{FiO}_{2}$ ventilation, Murray score $>3$ (weighted score of: CXR quadrants, $\mathrm{PaO}_{2} / \mathrm{FiO}_{2}$ ratio on $\mathrm{FiO}_{2} 1.0$, PEEP and lung compliance), severe hypercarbic $\mathrm{pH}<7.20$ with no contraindication(s) for anticoagulation. $\mathrm{ECCO}_{2} \mathrm{R}$ requires arterial and venous cannulation of femoral vessels, and an adequate cardiovascular reserve to drive the pumpless arterio-venous circuit.

While the use of ECMO in neonates is an established practice, ${ }^{6}$ it is not so in adults. Previous trials in adults with ECMO have failed to show any benefit, but were done during the era prior to 'rest setting' LPV. A trial of conventional ventilatory support versus ECMO for severe adult respiratory failure ${ }^{7}$ (CESAR trial, single-centre study) suggested an improvement in mortality (one extra survivor for every six patients treated) without disability at 6 months. This trial has been criticised ${ }^{7}$ for heterogeneity of ventilatory management in the conventional ventilation arm, and was a pragmatic trial concluded without adequate pretrial efficacy data.

Out of the 14 patients with $\mathrm{A}[\mathrm{H} 1 \mathrm{~N} 1]$ who required $\mathrm{MV}$ at our hospital this winter, only one patient was referred for ECMO, but did not receive it, similar to a published series from North America. ${ }^{2}$ We had no mortality from A[H1N1] in patients treated on our ICUs. However, the UK experience with A[H1N1] over the last two winters suggests that ECLS could have a role in managing severe refractory respiratory failure. We feel that as yet there is no convincing evidence to routinely advocate ECLS in failed conventional ventilation While there are calls for its routine implementation for patients with 'failing' conventional ventilation, strict adherence to LPV strategies, together with meticulous control of fluid balance (if required early renal replacement therapy) and inotropes to support the circulation and minimise VILI, may avoid the need for ECLS. Further randomised trials are still needed to identify the optimal place of ECLS within the current best practice management of refractory hypoxaemia. ${ }^{2}$

Funding Dr TV Veenith is supported by a clinical research training fellowship from the National Institute of Academic Anaesthesia (grant number RG61766 and RUAG/032)

Competing interests None.

Provenance and peer review Not commissioned; externally peer reviewed.

\section{REFERENCES}

1. Rowan KM, Harrison DA, Walsh TS, et al. The Swine Flu Triage (SwiFT) study: development and ongoing refinement of a triage tool to provide regular information to guide immediate policy and practice for the use of critical care services during the H1N1 swine influenza pandemic. Health Technol Assess 2010;14:335-492.

2. Miller RR 3rd, Markewitz BA, Rolfs RT, et al. Clinical findings and demographic factors associated with ICU admission in Utah due to novel 2009 influenza A(H1N1) infection. Chest 2010;137:752-8.

3. Mauad T, Hajjar LA, Callegari GD, et al. Lung pathology in fatal novel human influenza A (H1N1) infection. Am J Respir Crit Care Med 2010;181:72-9.

4. Petrucci N, lacovelli W. Lung protective ventilation strategy for the acute respiratory distress syndrome. Cochrane Database Syst Rev 2007;(3):CD003844.

5. Sud S, Sud M, Friedrich J0, et al. High frequency oscillation in patients with acute lung injury and acute respiratory distress syndrome (ARDS): systematic review and meta-analysis. BMJ 2010;340:c2327.

6. Gaffney AM, Wildhirt SM, Griffin MJ, et al. Extracorporeal life support. BMJ 2010;341:c5317.

7. Peek GJ, Elbourne D, Mugford M, et al. Randomised controlled trial and parallel economic evaluation of conventional ventilatory support versus extracorporeal membrane oxygenation for severe adult respiratory failure (CESAR). Health Technol Assess 2010;14:1-46. 